\title{
Serological profiles in nursery piglets colonized with Staphylococcus aureus
}

\author{
Florence Crombé ${ }^{1,2^{*}}$, Wannes Vanderhaeghen ${ }^{1,2}$, Corné P de Vogel ${ }^{3}$, Willem J Van Wamel ${ }^{3}$, Kurt Barbé ${ }^{4}$, \\ Katleen Hermans ${ }^{2}$, Freddy Haesebrouck ${ }^{2}$ and Patrick Butaye ${ }^{1,2}$
}

\begin{abstract}
At present, the immune response of pigs in relation to Staphylococcus aureus carriage is poorly understood. This study was aimed at investigating the dynamics of the anti-staphylococcal humoral immune response in methicillin-susceptible S. aureus (MSSA)-positive piglets and at assessing the effect of the experimental introduction of a methicillin-resistant S. aureus (MRSA) Sequence Type (ST) 398 strain. Therefore, serum samples were collected at different times from 31 weaned piglets originating from four different sows. Twenty-four out of the 31 piglets were challenged with MRSA ST398. The serum samples were analyzed for $\lg G$ antibodies to $39 \mathrm{~S}$. aureus antigens, using a multiplex bead-based assay (xMAP technology, Luminex Corporation). Though antibody responses showed broad inter-individual variability, serological results appeared to be clustered by litter of origin. For most antigens, an age-related response was observed with an apparent increase in antibody titers directed against staphylococcal microbial surface components recognizing adhesive matrix molecules (MSCRAMM), which have been shown to play a role in S. aureus colonization. In most animals, antibody titers directed against staphylococcal toxins or immune-modulating proteins decreased with age, possibly reflecting the absence of bacterial invasion. The introduction of MRSA ST398 did not elicit a significant humoral immune reaction.

This study describes, for the first time, the humoral immune response in weaned pigs colonized with $S$. aureus.
\end{abstract}

\section{Introduction}

Staphylococcus aureus is an opportunistic pathogen residing on the skin and mucous membranes of humans and several animal species [1,2]. In humans, it has been shown that nasal $S$. aureus carriage increases the risk of infection by a factor three, with patients being mostly affected by their autologous strain [3]. Conversely, a lower risk for bacteremia-related death has been reported in S. aureus carriers compared to non-carriers [3].

The differences in risk and outcome of $S$. aureus infections between human carriers and non-carriers have been associated with the humoral immune response, protecting carriers from bacteremia mediated death and non-carriers from $S$. aureus colonization. This response might include antibodies against staphylococcal microbial surface components recognizing adhesive matrix

\footnotetext{
* Correspondence: flcro@coda-cerva.be

${ }^{1}$ Veterinary and Agrochemical Research Centre (VAR), Department of Bacterial Diseases, Groeselenberg 99, Ukkel, Belgium

${ }^{2}$ Ghent University, Faculty of Veterinary Medicine, Department of Pathology, Bacteriology and Avian Diseases, Salisburylaan 133, Merelbeke 9820, Belgium Full list of author information is available at the end of the article
}

molecules (MSCRAMM) and against virulence factors involved in evading or destroying host defenses [4-8].

The extensive spread of livestock-associated methicillinresistant S. aureus (LA-MRSA) clonal complex (CC) 398 and CC9 among pigs has raised questions on the mechanisms establishing the interactions between MRSA and pigs [9-11]. As in humans, the pigs' immune system might play an important regulatory role. However, at present, knowledge on the (humoral) immune response of pigs to S. aureus is lacking. Therefore, our aim was to increase the understanding of this topic.

In the present study, we examined the kinetics of antistaphylococcal antibodies in weaned piglets colonized with $S$. aureus by determining the levels of IgG antibodies to 9 MSCRAMM, 23 staphylococcal toxins and 7 immune-modulating proteins in serum samples. In addition, we investigated the effect of the introduction of a MRSA Sequence Type (ST) 398 strain on the piglets' humoral immune response.

\section{Biomed Central}

(c) 2013 Crombé et al.; licensee BioMed Central Ltd. This is an Open Access article distributed under the terms of the Creative Commons Attribution License (http://creativecommons.org/licenses/by/2.0), which permits unrestricted use, distribution, and reproduction in any medium, provided the original work is properly cited. 


\section{Materials and methods}

\section{Animals and serum samples}

Venous blood samples were obtained from 31 healthy weaned cross-bred piglets (Landrace $\times$ Piétrain, MalèvesSt. Marie, Belgium) previously described in a transmission study with MRSA strain C26 (ST398, spa type t011, SCCmec type V) [12]. Briefly, at 21 days of age, piglets obtained from four different sows (1-4), were transported to the experimental site and distributed into three experimental groups (1-3) consisting of eight piglets, and one negative control group of seven piglets. All three experimental groups included four male and female pairs originating from each of the four sows. The negative control group was composed of three male and female pairs, originating from sows $1-3$, and a single female piglet originating from the fourth sow. The transmission study was performed by introducing two MRSA-positive animals (i.e. seeders that were inoculated with $\sim 9 \times 10^{8} \mathrm{CFU}$ of MRSA strain C26 two days before their introduction), at 30 days of age, in each experimental group composed of six MRSA-negative piglets. Swab samples from all animals were collected separately from both anterior nares, the skin behind the ears and the perineum, during a period of six weeks to determine their $S$. aureus carriage state. For the present study, serum samples were taken before the start of the transmission experiment (six days before introduction of the MRSA positive animals - age: 24 days) and at 8,15 , 22,29 and 36 days post introduction, corresponding to 38 , $45,52,59$ and 66 days of age.

Testing at 24 days of age revealed that all animals were positive for methicillin-susceptible $S$. aureus (MSSA) ST9 (spa type $\mathrm{t} 3446$ or $\mathrm{t} 337$ ). In all 24 animals that were included in the MRSA transmission study, MSSA and/or MRSA were detected until the end of the trial [12]. In the seven animals of the negative control group that were not colonized with MRSA strain C26, MSSA was not detected after the second sampling occasion, except once for one animal at the end [12]. To evaluate the effect of MRSA strain C26 introduction on the piglets' humoral response, animals were classified as persistent MRSA carriers $(n=8)$ if $\geq 80 \%$ of the samples taken at different time points after the introduction of MRSA were MRSA positive. Animals were classified as nonMRSA carriers $(n=7)$ if all samples were MRSA negative; the other animals were classified as intermittent MRSA carriers $(n=16)$.

\section{S. aureus strain characteristics}

The presence of 39 virulence-associated genes (Table 1) was determined in one MSSA isolate of each spa type originating from one randomly selected animal at 24 days of age and in MRSA strain C26 by DNA microarray by Alere Technologies GmbH, Jena, Germany [13-15].

\section{Anti-staphylococcal antibody assay}

Levels of IgG directed against 39 S. aureus proteins were quantified simultaneously using a bead-based flow cytometry technique (xMap; Luminex Corporation, Austin, TX, USA) based on a previously described method $[5,6]$. Briefly, serum samples were diluted 1:50 in PBS-BN (PBS, $1 \%$ bovine serum albumin, and $0.05 \%$ sodium azide [pH7.4]) for measurements of antigen-specific IgG. Per diluted sample, $50 \mu \mathrm{L}$ was incubated with the different fluorescence-coloured antigen-coupled microspheres, i.e. 3000 beads per antigen per well, in a 96-well filter microplate (Millipore, Amsterdam, The Netherlands) for $35 \mathrm{~min}$ at room temperature on a Thermomixer plate shaker (Eppendorf, Nijmegen, The Netherlands). After washing the plate twice with PBS-BN and aspiration by vacuum manifold, $50 \mu \mathrm{L}$ of a 1:100 dilution of R-phycoerythrin (RPE)-labelled anti-swine IgG (Jackson Immuno Research, Westgrove, PA, USA) was added. Following a second incubation (35 min at room temperature) and washing step, the microspheres were resuspended in $100 \mu \mathrm{L}$ PBS-BN. Measurements were performed on the Luminex 100 instrument (BMD, Croissy-Beaubourg, France) using Luminex software (version 2.2). Tests were performed in independent duplicates and the median fluorescence intensity (MFI) values, reflecting semi-quantitative antibody levels, were averaged. Duplicates with a coefficient of variance (CV) higher than $25 \%$ were considered as not reproducible and deleted from the data set. If antibody binding was observed in the serum samples incubated with the control beads (i.e. beads without protein coupled on their surface), the nonspecific MFI values were subtracted from the antigen-specific results. Swine pooled serum, collected from 85 healthy pigs, incubated with protein-coupled beads was used as a positive control. Similarly, PBS-BN was included as a negative control.

\section{Statistical analysis}

Independent-sample median test was performed to determine the distribution across the animals grouped by litter of origin with a 0.05 threshold at 24 days of age (SPPS software, version 19) [16].

The kinetics of anti-staphylococcal antibodies were analyzed using linear regression during a 6-week period. A linear mixed model including fixed and random effects was used by means of the MIXED procedure of SPPS software, version 19. The model was fitted using the Maximal Likelihood estimation (ML) method and used to evaluate the effect of MRSA ST398 introduction on the antibody profiles of the piglets. Age (in days), group (non-MRSA carriers vs. persistent and intermittent MRSA carriers) and gender (male vs. female) were introduced as fixed effects. To increase the degrees of freedom in the statistical analysis, the factor "age" was not included as a repeated measure, though the different 
Table 1 DNA microarray results for the 39 S. aureus antigens studied by Luminex assay Antigens of S. aureus Full name

DNA microarray results ST398-V/t011 ST9/t3446

\begin{tabular}{|c|c|c|c|c|}
\hline \multicolumn{5}{|c|}{ MSCRAMM } \\
\hline ClfA & clumping factor $\mathrm{A}$ & + & + & + \\
\hline ClfB & clumping factor $B$ & + & + & + \\
\hline$\overline{F n b p A}$ & fibronectin binding protein $A$ & + & + & + \\
\hline FnbpB & fibronectin binding protein $B$ & + & + & + \\
\hline $\mathrm{IsdA}$ & iron-responsive surface determinant $A$ & + & + & + \\
\hline$\overline{\mathrm{IsdH}}$ & iron-responsive surface determinant $\mathrm{H}$ & ND & ND & ND \\
\hline SasG & surface protein $\mathrm{G}$ & - & - & - \\
\hline $\mathrm{SdrD}$ & serine-aspartate dipeptide repeat $\mathrm{D}$ & + & + & + \\
\hline SdrE & serine-aspartate dipeptide repeat $\mathrm{E}$ & ND & ND & ND \\
\hline \multicolumn{5}{|c|}{ Immune-modulating proteins } \\
\hline CHIPS & chemotaxis inhibitory protein of S. aureus & - & - & - \\
\hline $\mathrm{SCIN}$ & staphylococcal complement inhibitor & - & - & - \\
\hline SSL1 & S. aureus surface protein like 1 & + & + & + \\
\hline SSL3 & S. aureus surface protein like 3 & $-*$ & + & + \\
\hline$\overline{S S L 5}$ & S. aureus surface protein like 5 & + & + & + \\
\hline$\overline{S S L 9}$ & S. aureus surface protein like 9 & + & + & + \\
\hline$\overline{S S L 11}$ & S. aureus surface protein like 11 & - & - & - \\
\hline \multicolumn{5}{|c|}{ Leucotoxins } \\
\hline $\mathrm{HlgB}$ & haemolysin beta & $+^{* *}$ & + & + \\
\hline LukD & leukocidin D & - & - & - \\
\hline LukE & leukocidin $\mathrm{E}$ & - & - & - \\
\hline LukF & leukocidin F & + & + & + \\
\hline LukS & leukocidin S & + & + & + \\
\hline \multicolumn{5}{|c|}{ Staphylococcal enterotoxins } \\
\hline a-toxin & alfa-toxin & + & + & + \\
\hline SEA & staphylococcal enterotoxin A & - & - & - \\
\hline SEB & staphylococcal enterotoxin B & - & - & - \\
\hline SEC & staphylococcal enterotoxin C & - & - & - \\
\hline SED & staphylococcal enterotoxin D & - & - & - \\
\hline$\overline{\text { SEE }}$ & staphylococcal enterotoxin E & - & - & - \\
\hline$\overline{\text { SEG }}$ & staphylococcal enterotoxin G & - & + & + \\
\hline$\overline{\mathrm{SEH}}$ & staphylococcal enterotoxin $\mathrm{H}$ & - & - & - \\
\hline SEl & staphylococcal enterotoxin I & - & + & + \\
\hline SEJ & staphylococcal enterotoxin J & - & - & - \\
\hline SEM & staphylococcal enterotoxin M & - & + & + \\
\hline SEN & staphylococcal enterotoxin $\mathrm{N}$ & - & + & + \\
\hline SEO & staphylococcal enterotoxin $\mathrm{O}$ & - & + & + \\
\hline SEQ & staphylococcal enterotoxin Q & - & - & - \\
\hline SER & staphylococcal enterotoxin R & - & - & - \\
\hline TSST-1 & toxic shock syndrome toxin-1 & - & - & - \\
\hline \multicolumn{5}{|c|}{ Exfoliative toxins } \\
\hline ETA & exfoliative toxin $\mathrm{A}$ & - & - & - \\
\hline$\overline{\text { ETB }}$ & exfoliative toxin $B$ & - & - & - \\
\hline
\end{tabular}

ND: Not determined.

*- for Staphylococcal Superantigen like protein $8 / \mathrm{SSL} 3,+$ for Staphylococcal Superantigen like protein B3.

**+ for un-truncated Haemolysin Beta. 
sampling occasions are dependent, because of the limited data of the study. However, the interaction term "age"group" was added to correct for the time effect. In this way changes between groups over time could be observed. The piglets and their respective mothers (i.e. the interaction term "pig*sow") were introduced as random effect to account for piglet and sow individual effects and disturbances.

\section{Results}

\section{S. aureus strain characteristics}

The presence of genes encoding virulence factors included in the antibody assay in the studied S. aureus strains is mentioned in Table 1.

\section{Anti-staphylococcal antibody response Overall antibody response over time}

IgG antibodies were detected in the positive control sample (swine pooled serum) for all but one (i.e. SEB) antigen. The negative control (PBS-BN) incubated with protein-coupled beads resulted in low MFI values $(<9)$. Serum incubated with control beads resulted in median MFI values of 208 (range: 83-606). Two samples were deleted from the data set, corresponding to serum of an animal at 24 days of age and one at 59 days of age, because the first one had high control bead levels (MFIvalue of 1969) and the other one showed MFI-values similar to the PBS-BN. Both piglets belong to the persistent MRSA carrier group.
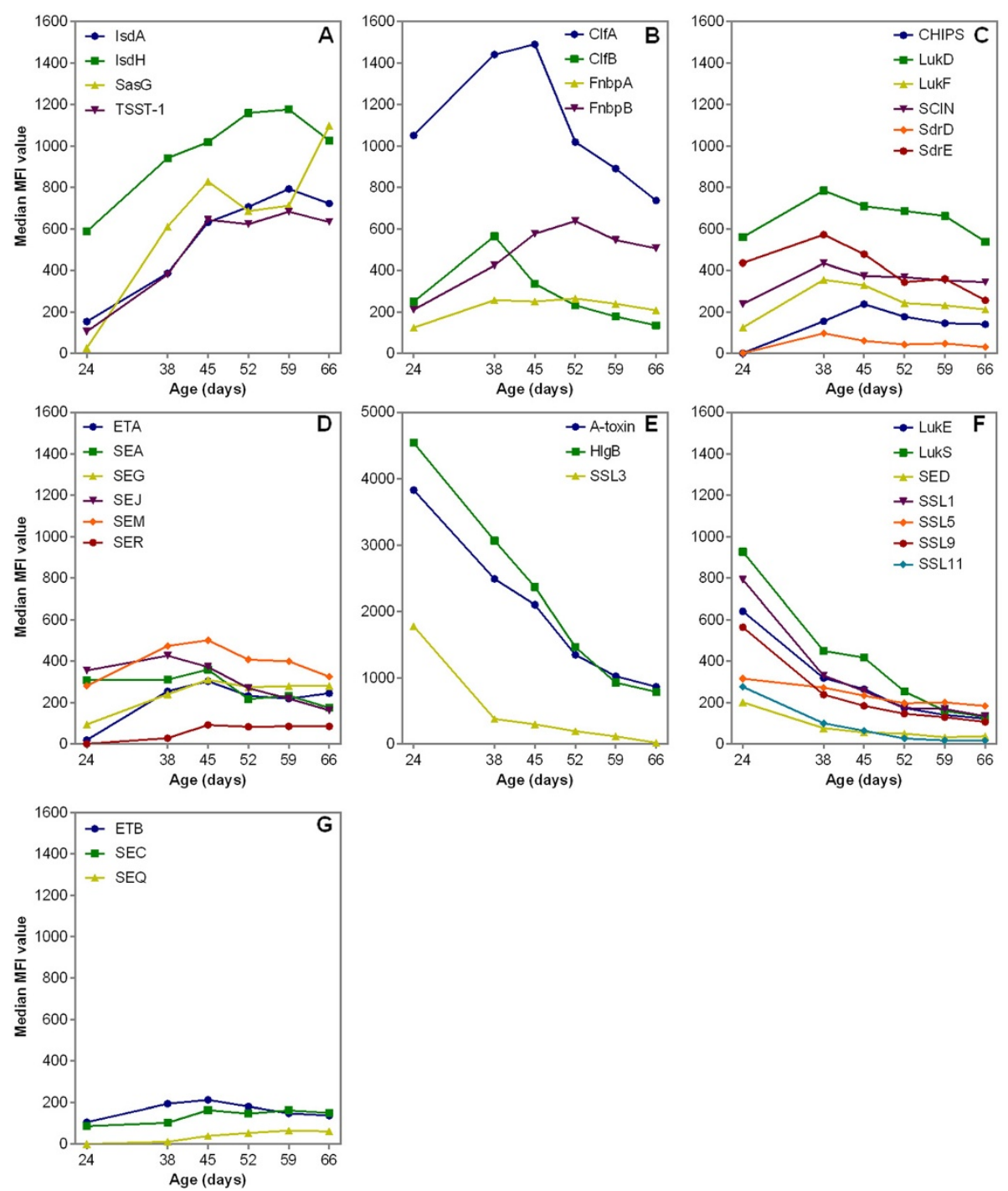

Figure 1 Median of the median fluorescence intensity (MFI) values reflecting lgG levels for $33 \mathrm{~S}$. aureus antigens in 31 piglets over 6 weeks. Four trends were observed: increasing antibody levels $(\mathbf{A})$, increasing antibody levels followed by a slow decline (B,C,D), decreasing antibody levels $(\mathbf{E}, \mathbf{F})$ and nearly no varying antibody levels over time $(\mathbf{G})$. 
Median MFI values reflecting IgG levels against six out of $39 \mathrm{~S}$. aureus antigens were nearly absent in the piglets' serum samples, i.e. SEB, SEE, SEH, SEI, SEN and SEO (median MFI < 1) (data not shown). As a result, the antibody response against these antigens will not be further discussed.

As shown in Figure 1, four antibody response trends could be observed over the 6-week period: i. continuously increasing antibody levels over time (A), ii. increasing antibody levels followed by a slow decline over time (B,C,D), iii. a high antibody level at the start that decreased over time (E,F) and iv. nearly no varying antibody levels over time (G). In line with these observations, a significant "time" effect was observed $(p<0.05)$ for all but two of the 33 antigens (i.e. ETB and SEC) (data not shown).

\section{Antigen-specific antibody levels classified per sow}

Although antibody levels varied among the animals, the IgG levels directed against several antigens appeared to be grouped by litter of origin (Figure 2). These data are presented in an additional data file (see Additional file 1). An independent-sample median test revealed that the distributions across the animals grouped by litter of origin were significantly different for 24 out of the 33 antigens tested at 24 days of age $(p<0.05)$ (Figure 2$)$. Also, when focusing on the antigens with decreasing global antibody profiles (i.e., $\alpha$-toxin, HlgB, SSL1, SSL3, SSL5, SSL9, SSL11, LukE and LukS), a litter-related decrease was perceived over time (Figure 3). Remarkably though as a general

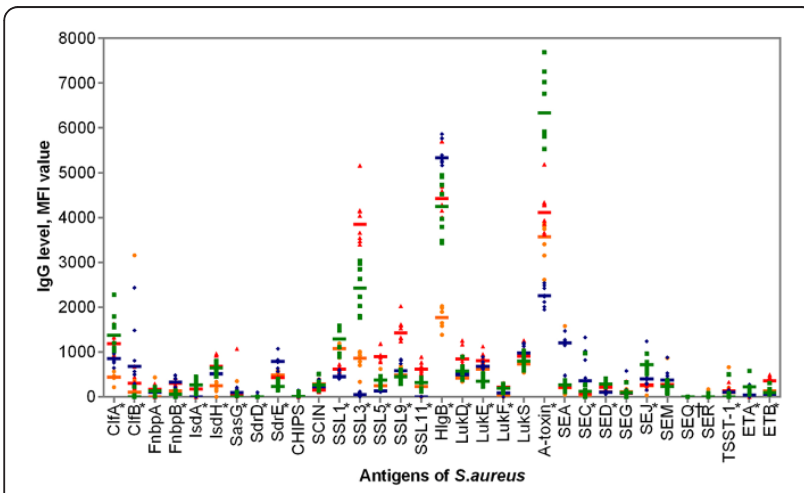

Figure 2 Median fluorescence intensity (MFI) value reflecting IgG levels for $33 \mathrm{~S}$. aureus antigens in 30 piglets classified per litter at $\mathbf{2 4}$ days of age. Each dot represents a single piglet, green squares represent litter 1, blue diamonds represent litter 2, red triangles represent litter 3 and orange spheres represent litter 4 . Median lgG levels are indicated by horizontal lines. *Significant with independent-sample median test across animals grouped by litter at 24 days of age (a-toxin, FnbpB, SED, SSL1, SSL3 and SSL5, $p<0.001$; ClfA, ClfB, ETA, HlgB, IsdA, IsdH, LukE, LukF, SdrE, SEJ, SSL9 and SSL11, $p<0.005$; ETB, LukD, $p<0.01$; SasG, SdrD, SEC and TSST-1, $p<0.05$ ); † Unable to compute for SEQ. trend, the levels of antibodies against $\alpha$-toxin and SSL1 declined, it appeared that IgG levels increased for certain animals at 59 and 66 days of age (Figure 4).

\section{Effect of MRSA introduction on antibody profiles}

The 'group' effect was significant for one antigen (i.e. ClfB, $p=0.014$ ), with mean IgG levels being significantly lower in persistent MRSA carriers compared with non-MRSA carriers $(p=0.031)$. Mean IgG levels directed against ClfB were lower (though not significant) in intermittent MRSA carriers compared with non-MRSA carriers $(p=0.09)$ (data not shown).

The humoral immune response to ClfA, ClfB, ETB and FnbpB differed significantly between groups over time (age ${ }^{*}$ group interaction; $p<0.001, p=0.001, p=0.035$ and $p=0.006$, respectively). At the peak of the IgG response (38 days of age), antibody levels directed against ClfA and ETB were significantly higher in non-MRSA carriers compared to persistent MRSA carriers $(p<0.001 ; p=0.003)$ and intermittent MRSA carriers $(p=0.007 ; p=0.006)$ (Figure 5). For ClfB, antibody levels were significantly higher in non-MRSA carriers compared to intermittent MRSA carriers $(p<0.001)$ though not compared to persistent MRSA carriers $(p=0.12)$ (Figure 5). Conversely, for FnbpB, antibody levels were significantly higher in non-MRSA carriers compared to persistent MRSA carriers $(p=0.003)$ though not compared to IC $(p=0.058)$ (Figure 5$)$. However, for ETB, one non-MRSA carrier had a very high IgG level at 38 days of age and when deleting this record from the dataset a significant difference was no longer observed (age $\mathrm{e}^{*}$ group interaction; $p=0.77$ ).

When deleting an additional non-MRSA carrier from the dataset, with high levels directed against ClfA and FnbpB at 38 days of age, a significant difference was also no longer observed (age* group interaction; $p=0.094$ and $p=0.075$ ).

For each sampling occasion, mean IgG levels $\pm 95 \% \mathrm{CI}$ of intermittent MRSA carriers, persistent MRSA carriers and non-MRSA carriers are presented in an additional data file (see Additional file 2).

\section{Discussion}

To our knowledge, this is the first study on humoral immune response against $S$. aureus in weaned pigs. We used a multiplex bead-based assay (xMAP technology, Luminex Corporation) to simultaneously quantify antibodies against 39 staphylococcal proteins in small-volume serum samples. This high-throughput immunological test is of particular interest since it gives the opportunity to simultaneously study the humoral response of healthy or diseased individuals to a specific pathogen towards large sets of antigens $[5,6,17,18]$.

Antibodies against all but one of the 39 antigens (i.e. SEB) were detected in the swine pooled serum standard positive control. Therefore, the present study does not allow drawing conclusions with regards to serological 

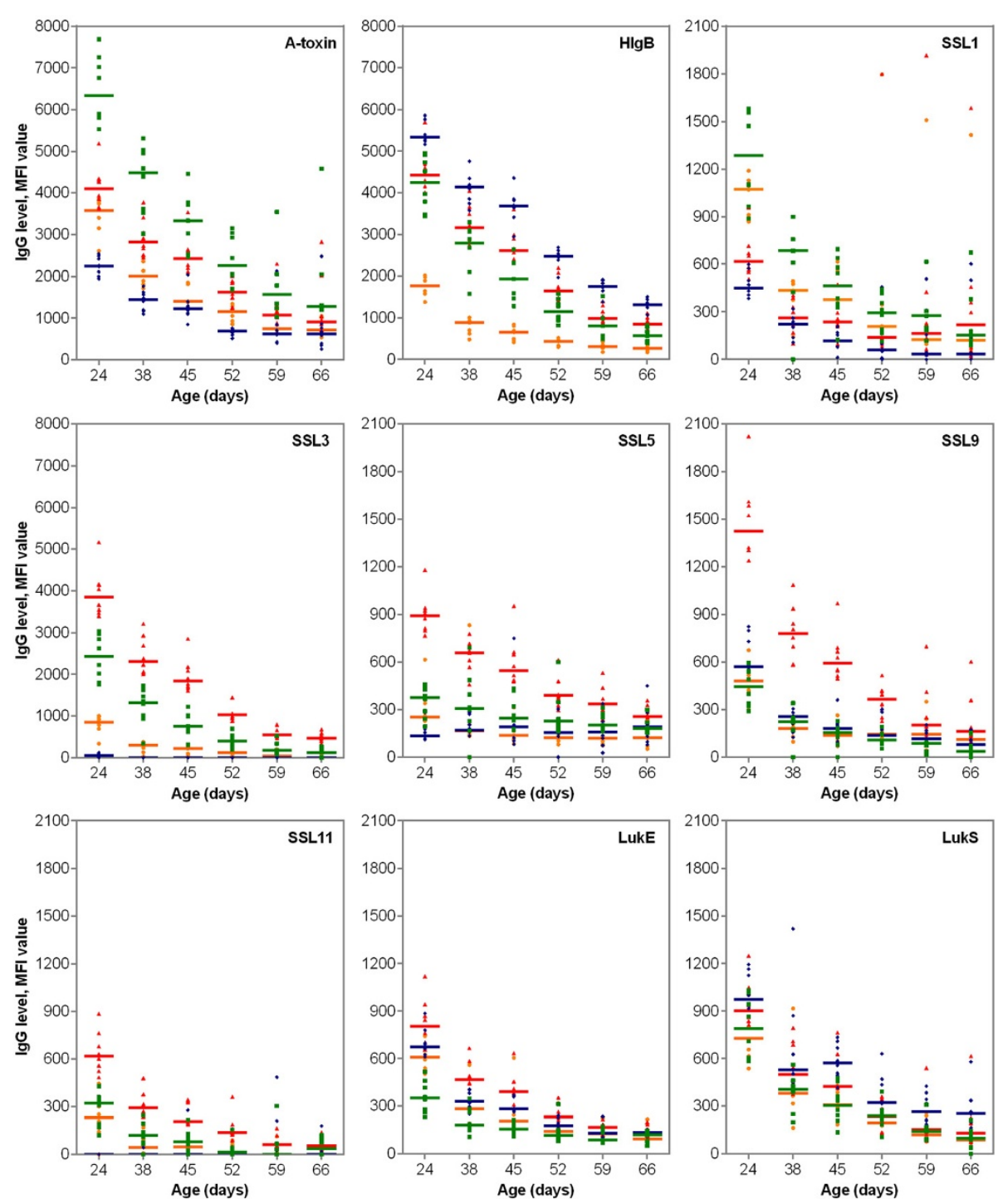

Figure 3 Median fluorescence intensity (MFI) values reflecting lgG levels against a-toxin, HlgB, SSL1, SSL3, SSL5, SSL9, SSL11, LukE and LukS in 31 piglets classified per litter over a 6-week period. Each dot represents a single piglet, green squares represent litter 1, blue diamonds represent litter 2, red triangles represent litter 3 and orange spheres represent litter 4 . Median lgG levels are indicated by horizontal lines.

responses to SEB. However, given that SEB is generally absent in S. aureus strains of animal origin [19], which was also the case for the investigated strains, it is unlikely that pigs produced antibodies against this antigen.

Four trends were observed among the dynamics of antistaphylococcal antibody response in all piglets colonized with $S$. aureus: i. a main increase in response over time, ii. an increase in response followed by a slow decline, iii. a main decrease in response over time or iv. almost no change in response. Given that the observational period of the present study started at weaning, it is likely that serum IgG directed against certain antigens are de novo synthesized by the piglets whereas others are of maternal origin $[20,21]$. Increasing antibody titers indicate de novo synthesis, whereas antibodies with decreasing titers are most probably from maternal origin. Interestingly, most antibodies with increasing levels were directed to antigens belonging to the family of the MSCRAMM, which are known to be expressed by actively dividing bacteria and are essential in the colonization process of S. aureus [2,22-24]. This indicates that maternal antibodies do not protect piglets from colonization. Indeed, it has been described that piglets derived from $S$. aureus-positive sows are more likely to become $S$. aureus colonized [25]. In contrast, antibodies with decreasing levels were mostly directed against staphylococcal toxins or immune-modulating proteins interfering with host defences and playing a role during staphylococcal invasion $[5,6]$. 

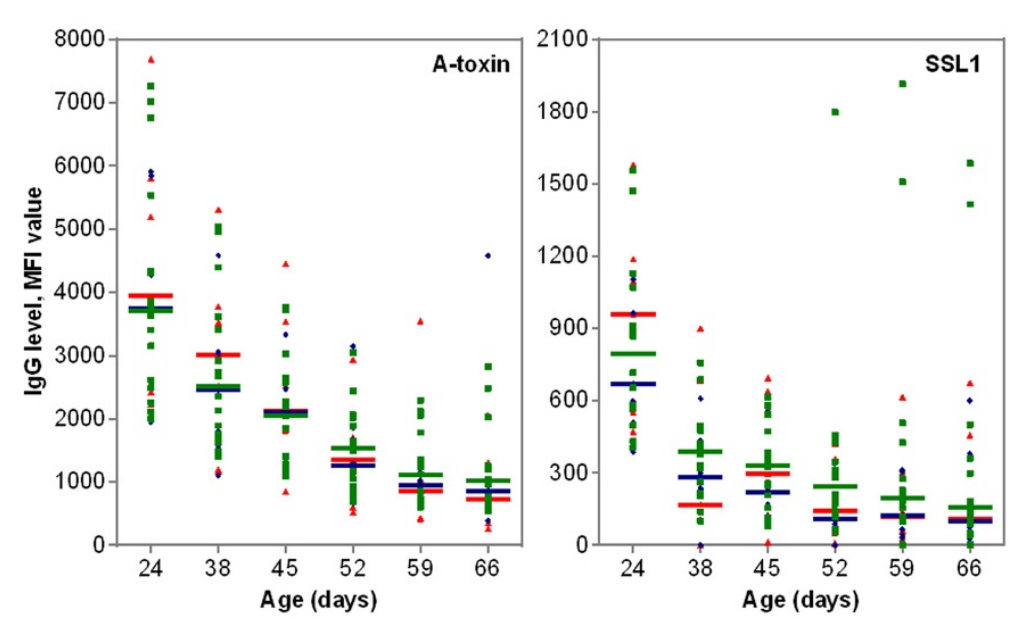

Figure 4 Median fluorescence intensity (MFI) values reflecting lgG levels against a-toxin and SSL1 in 31 piglets classified per MRSA carrier group over a 6-week period. Each dot represents a single piglet, green squares represent intermittent MRSA carriers $(n=16)$; blue diamonds represent persistent MRSA carriers $(n=8)$, red triangles represent non-MRSA carriers $(n=7)$. Median IgG levels are indicated by horizontal lines.
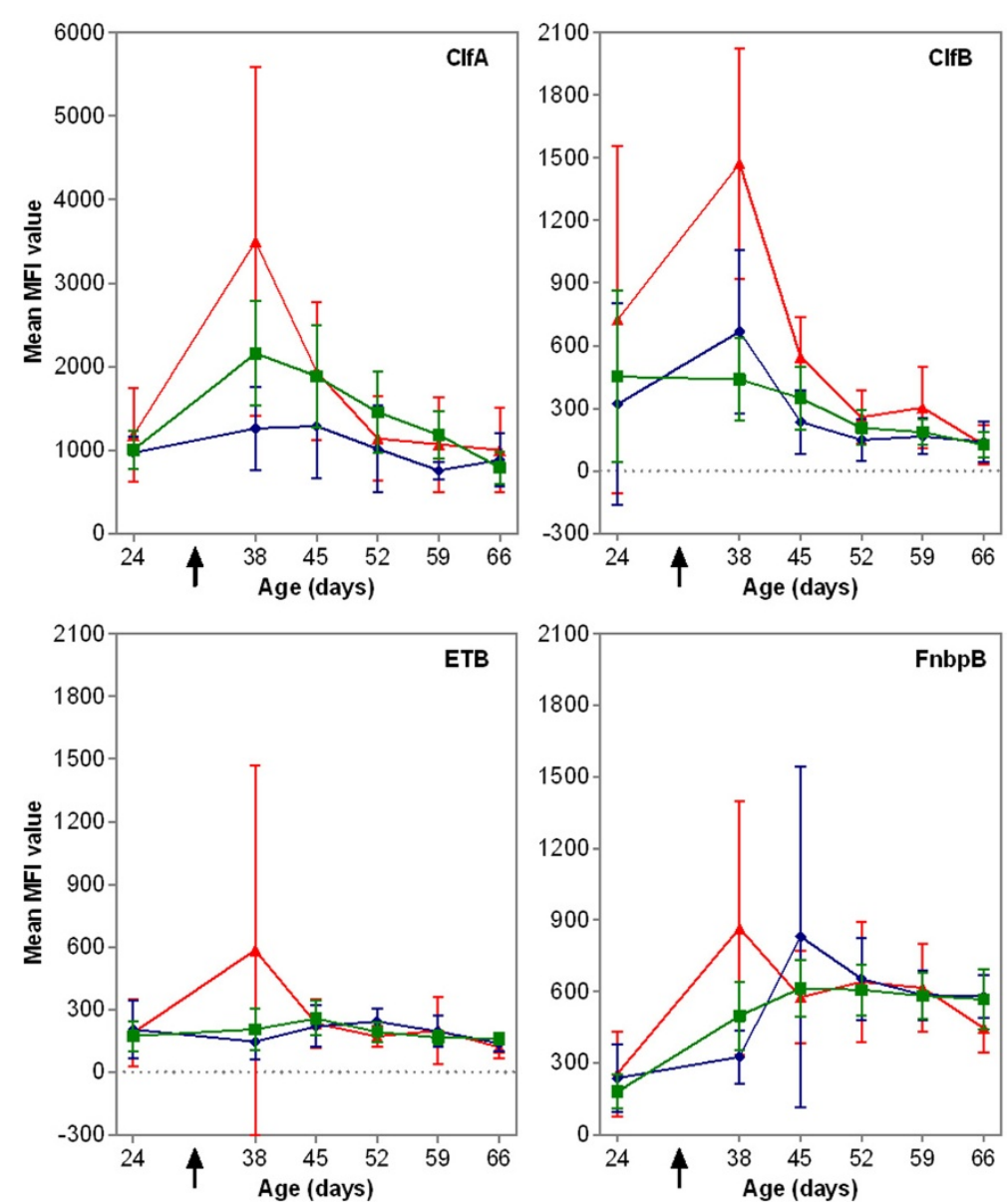

Figure 5 Mean of the median fluorescence intensity (MFI) values reflecting lgG levels for ClfA, ClfB, ETB and FnbpB per MRSA carrier group over time. Green squares represent intermittent MRSA carriers $(n=16)$; blue diamonds represent persistent MRSA carriers $(n=8)$, red triangles represent non-MRSA carriers $(n=7)$. Data are presented as mean $\pm 95 \% \mathrm{Cl}$. $\uparrow:$ MRSA introduction. 
For certain antigens, antibody response was observed though the corresponding genes were not detected on the microarray in the investigated $S$. aureus strains. Hence, it must be noted that the microarray technology used here bears some limitation as it only detects genes matching the probes printed on the array. Given that this composite multi-strain array covers allelic variants of genes of $S$. aureus genomes of diverse human and bovine lineages, allelic variants specific for porcine ST398 and ST9 strains might be missing $[14,15,26]$. For example, Schijffelen [27] reported that a $s c n$ gene homologue encoding SCIN was present on a novel 'animal-specific' staphylococcal pathogenicity island (SaPI-S0385), in MRSA ST398 strain S0385 that was not included on the array. Similarly, a chp gene homologue coding for Fprl1 inhibitory protein (Flipr) [28], a CHIPS homologue, has been described in MRSA ST398 strain S0385. Another explanation might be that other non$S$. aureus staphylococcal species, present on the piglets' mucosae, express S. aureus like antigens. Several studies reported a high occurrence of non-S. aureus staphylococci in the nares of pigs [29-32] and it has been shown that staphylococcal species share a common reservoir of virulence factors [33-35]. Notably, S. aureus and Staphylococcus hyicus, a pathogen causing exudative epidermitis in pigs and a staphylococcal species commonly found in pigs' endogenous flora [29,36], carry related ETB [33], which might explain the high IgG levels observed in a 38-day-old animal in the present study though ETB was absent in the investigated $S$. aureus strains.

On the contrary, IgG levels against several enterotoxins (i.e. SEI, SEO, SEN) - encoded on the enterotoxin gene cluster $(e g c)$ - were nearly absent though genes coding for these factors were present in the investigated $S$. aureus strains. Staphylococcal enterotoxins are likely to be mainly expressed during infection and less during colonization, which might explain the absence of antibodies in sera from healthy pigs. Antibodies against egc enterotoxins are also rarely detected in sera from healthy humans [37].

The introduction of MRSA strain C26 at weaning appeared not to increase the anti-staphylococcal antibody titers. These observations indicate a low immunogenic potential of strain C26 during colonization. However, since the observational period is at weaning, maternal antibodies might have interfered with the piglets' response $[20,21]$. Furthermore, conventional pigs naturally colonized with $S$. aureus and having normal microbiota, including various staphylococcal species [30,38], were used in the present study. Though our trial resembles MRSA colonization as noticed in the field situation on many pig herds $[9,25]$, using such pigs complicates the interpretation of the immune response against the MRSA ST398 strain used here. Indeed, in the present study, IgG levels directed against ClfA, ClfB and FnbpB were significantly lower in persistent MRSA carriers and/or intermittent MRSA carriers compared to non-MRSA carriers at 38 days of age. This might indicate that MRSA ST398 strain C26 suppresses systemic antibody responses against certain $S$. aureus antigens thus possibly facilitating its colonization. However, since extensive inter-individual differences were observed, these significant effects appeared to result from few animals for ClfA and FnbpB. Future studies with caesarean-derived colostrum-deprived piglets may help to further elucidate the immune response associated with MRSA colonization, although this is a more artificial model [39]. In addition, the immunogenic potential of highly virulent MRSA clones such as the community-associated MRSA-like ST8 clone, known as USA300, recently isolated from pigs in Peru [40] and USA [41], are interesting issues to consider in further studies. In that way, the effect of strongly immunogenic extracellular toxins such as PantonValentine leukocidin, a cytotoxin which is probably associated with necrotizing lesion development, and additional enterotoxins on the humoral immune response of piglets could be studied.

Since the focus has been set on serum IgG which dominates the systemic immunity, the possible role of IgA involved in the mucosal immune system, remains to be investigated [20,42-44]. Also, the cellular immune response after $S$. aureus colonization should be investigated.

In conclusion, this is the first report on the humoral immune response in weaned pigs colonized with $S$. aureus. Antibody titers directed against MSCRAMM increased over time whereas antibody titers directed against staphylococcal toxins or immune-modulating proteins decreased, which might partly reflect the role of specific antigens in $S$. aureus colonization. The introduction of MRSA ST398 did not elicit a significant humoral immune reaction. The presence of maternally derived immunity and other staphylococcal species in the piglets' microbiota may have influenced the results of the present study.

\section{Additional files}

Additional file 1: Median fluorescent intensity (MFI) values reflecting antigen-specific immunoglobulin (Ig) G levels between litters at $\mathbf{2 4}$ days of age.

Additional file 2: Median fluorescent intensity (MFI) values reflecting antigen-specific immunoglobulin (Ig) G levels between intermittent MRSA carriers, persistent MRSA carriers and non-MRSA carriers during 6 weeks.

Competing interests

The authors declare that they have no competing interests.

\section{Authors' contributions}

Experimental design and planning: $\mathrm{FC}, \mathrm{KH}, \mathrm{FH}, \mathrm{PB}$; animal experiments: $\mathrm{FC}$; serological analysis CPDV, WJWW; data processing and statistical analysis FC, CPDV, WJWW, KB; drafting of the manuscript: FC, W; critical revision of the manuscript: CPDV, WJWW, KB, KH, FH, PB. All authors read and approved the manuscript. 


\section{Acknowledgements}

This study was approved by the Veterinary and Agrochemical Research Centre (VAR) animal care committee and financial support was received from the Institute for the Promotion of Innovation by Science and Technology in Flanders (IWT) project 070596.

We thank Willem Van Campe and his team for excellent technical assistance.

\section{Author details}

'Veterinary and Agrochemical Research Centre (VAR), Department of Bacterial Diseases, Groeselenberg 99, Ukkel, Belgium. ${ }^{2}$ Ghent University, Faculty of Veterinary Medicine, Department of Pathology, Bacteriology and Avian Diseases, Salisburylaan 133, Merelbeke 9820, Belgium. ${ }^{3}$ Erasmus Medical Centre, Departments of Medical Microbiology and Infectious Diseases, 's-Gravendijkwal 230, Rotterdam, The Netherlands. "Vrije Universiteit Brussel, Faculty of Engeneering, Deptartment of fundamental electricity and instrumentation (ELEC), Pleinlaan 2, Brussels, Belgium.

Received: 16 July 2012 Accepted: 11 January 2013

Published: 22 January 2013

\section{References}

1. Gordon RJ, Lowy FD: Pathogenesis of methicillin-resistant Staphylococcus aureus infection. Clin Infect Dis 2008, 46(Suppl 5):S350-359.

2. Hermans K, Devriese LA, Haesebrouck F: Staphylococcus. In Pathogenesis of bacterial infections in animals. 4th edition. Edited by Gyles CL, Prescott JF, Songer JG, Thoen CO. USA: Wiley-Blackwell; 2010:75-89.

3. Wertheim HF, Vos MC, Ott A, van Belkum A, Voss A, Kluytmans JA, van Keulen PH, Vandenbroucke-Grauls CM, Meester MH, Verbrugh HA: Risk and outcome of nosocomial Staphylococcus aureus bacteraemia in nasal carriers versus non-carriers. Lancet 2004, 364:703-705.

4. Clarke SR, Brummell K, Horsburgh MJ, McDowell PW, Mohamad SA, Stapleton MR, Acevedo J, Read RC, Day NP, Peacock SJ, Mond JJ, Kokai-Kun JF, Foster SJ: Identification of in vivo-expressed antigens of Staphylococcus aureus and their use in vaccinations for protection against nasal carriage. J Infect Dis 2006, 193:1098-1108.

5. van Belkum A, Verkaik NJ, de Vogel CP, Boelens HA, Verveer J, Nouwen JL, Verbrugh HA, Wertheim HF: Reclassification of Staphylococcus aureus nasal carriage types. J Infect Dis 2009, 199:1820-1826.

6. Verkaik NJ, de Vogel CP, Boelens HA, Grumann D, Hoogenboezem T, Vink C, Hooijkaas H, Foster TJ, Verbrugh HA, van Belkum A, van Wamel WJ: Antistaphylococcal humoral immune response in persistent nasal carriers and noncarriers of Staphylococcus aureus. J Infect Dis 2009, 199:625-632.

7. Verkaik NJ, Lebon A, de Vogel CP, Hooijkaas H, Verbrugh HA, Jaddoe WW, Hofman A, Moll HA, van Belkum A, van Wamel WJ: Induction of antibodies by Staphylococcus aureus nasal colonization in young children. Clin Microbiol Infect 2010, 16:1312-1317.

8. Colque-Navarro P, Jacobsson G, Andersson R, Flock Jl, Mollby R: Levels of antibody against 11 Staphylococcus aureus antigens in a healthy population. Clin Vaccine Immunol 2010, 17:1117-1123.

9. EFSA: Analysis of the baseline-survey on the prevalence of methicillinresistant Staphylococcus aureus (MRSA) in holdings with breeding pigs, in the EU, 2008. Part A: MRSA prevalence estimates; on request from the European Commission. EFSA J 2009, 7:1376-82. doi:10.2903/.jefsa.2009.1376.

10. Neela V, Mohd Zafrul A, Mariana NS, van Belkum A, Liew YK, Rad EG: Prevalence of ST9 MRSA among pigs and pig handlers in Malaysia. J Clin Microbiol 2009, 47:4138-4140.

11. Wagenaar JA, Yue H, Pritchard J, Broekhuizen-Stins M, Huijsdens X, Mevius $D J$, Bosch T, van Duijkeren E: Unexpected sequence types in livestock associated methicillin-resistant Staphylococcus aureus (MRSA): MRSA ST9 and a single locus variant of ST9 in pig farming in China. Vet Microbiol 2009, 139:405-409

12. Crombé F, Vanderhaeghen W, Dewulf J, Hermans K, Haesebrouck F, Butaye P: Colonization and Transmission of Methicillin-Resistant Staphylococcus aureus ST398 in Nursery Piglets. Appl Environ Microbiol 2012, 78:1631-1634.

13. The Alere Technologies $\mathrm{GmbH}$ website [www.alere-technologies.com]

14. Monecke S, Kuhnert P, Hotzel H, Slickers P, Ehricht R: Microarray based study on virulence-associated genes and resistance determinants of Staphylococcus aureus isolates from cattle. Vet Microbiol 2007, 125:128-140.

15. Monecke S, Jatzwauk L, Weber S, Slickers P, Ehricht R: DNA microarraybased genotyping of methicillin-resistant Staphylococcus aureus strains from Eastern Saxony. Clin Microbiol Infect 2008, 14:534-545.
16. The SPSS software website [www.spss.com]

17. Shoma S, Verkaik NJ, de Vogel CP, Hermans PW, van Selm S, Mitchell TJ, van Roosmalen M, Hossain S, Rahman M, Endtz HP, van Wamel WJ, van Belkum A: Development of a multiplexed bead-based immunoassay for the simultaneous detection of antibodies to 17 pneumococcal proteins. Eur J Clin Microbiol Infect Dis 2011, 30:521-526.

18. van den Berg S, Bowden MG, Bosma T, Buist G, van Dijl JM, van Wamel WJ, de Vogel CP, van Belkum A, Bakker-Woudenberg IA: A multiplex assay for the quantification of antibody responses in Staphylococcus aureus infections in mice. J Immunol Methods 2011, 365:142-148.

19. Monecke S, Coombs G, Shore AC, Coleman DC, Akpaka P, Borg M, Chow H, Ip M, Jatzwauk L, Jonas D, Kadlec K, Kearns A, Laurent F, O'Brien FG, Pearson J, Ruppelt A, Schwarz S, Scicluna E, Slickers P, Tan HL, Weber S, Ehricht R: A field guide to pandemic, epidemic and sporadic clones of methicillinresistant Staphylococcus aureus. PLoS One 2011, 6:e17936.

20. Bailey M, Haverson K, Inman C, Harris C, Jones P, Corfield G, Miller B, Stokes $\mathrm{C}$ : The development of the mucosal immune system pre- and postweaning: balancing regulatory and effector function. Proc Nutr Soc 2005, 64:451-457.

21. Butler JE, Zhao Y, Sinkora M, Wertz N, Kacskovics I: Immunoglobulins, antibody repertoire and B cell development. Dev Comp Immunol 2009, 33:321-333.

22. Wertheim HF, Walsh E, Choudhurry R, Melles DC, Boelens HA, Miajlovic H, Verbrugh HA, Foster T, van Belkum A: Key role for clumping factor B in Staphylococcus aureus nasal colonization of humans. PLoS Med 2008, 5:e17.

23. Burian M, Rautenberg $M$, Kohler T, Fritz M, Krismer B, Unger C, Hoffmann WH, Peschel A, Wolz C, Goerke C: Temporal expression of adhesion factors and activity of global regulators during establishment of Staphylococcus aureus nasal colonization. J Infect Dis 2010, 201:1414-1421.

24. Burian M, Wolz C, Goerke C: Regulatory adaptation of Staphylococcus aureus during nasal colonization of humans. PLoS One 2010, 5:e10040.

25. Weese JS, Zwambag A, Rosendal T, Reid-Smith R, Friendship R: Longitudinal investigation of methicillin-resistant Staphylococcus aureus in piglets. Zoonoses Public Health 2011, 58:238-243.

26. McCarthy AJ, Lindsay JA: Genetic variation in Staphylococcus aureus surface and immune evasion genes is lineage associated: implications for vaccine design and host-pathogen interactions. BMC Microbiol 2010, 10:173.

27. Schijffelen MJ, Boel $\mathrm{CH}$, van Strijp JA, Fluit AC: Whole genome analysis of a livestock-associated methicillin-resistant Staphylococcus aureus ST398 isolate from a case of human endocarditis. BMC Genomics 2010, 11:376.

28. Prat C, Bestebroer J, de Haas CJ, van Strijp JA, van Kessel KP: A new staphylococcal anti-inflammatory protein that antagonizes the formyl peptide receptor-like 1. J Immunol 2006, 177:8017-8026.

29. Devriese LA: Staphylococci in healthy and diseased animals. Soc Appl Bacteriol Symp Ser 1990, 19:S71-80.

30. Baele M, Chiers K, Devriese LA, Smith HE, Wisselink HJ, Vaneechoutte M, Haesebrouck F: The gram-positive tonsillar and nasal flora of piglets before and after weaning. J Appl Microbiol 2001, 91:997-1003.

31. Tulinski P, Fluit AC, Wagenaar JA, Mevius D, van de vijver $L$, Duim B: Methicillin-resistant coagulase-negative staphylococci on pig farms as a reservoir of heterogeneous staphylococcal cassette chromosome mec elements. Appl Environ Microbiol 2012, 78:299-304.

32. Vanderhaeghen $W$, Vandendriessche $S$, Crombé F, Dispas M, Denis $O$, Hermans K, Haesebrouck F, Butaye P: Species and staphylococcal cassette chromosome mec (SCCmec) diversity among methicillin-resistant nonStaphylococcus aureus staphylococci isolated from pigs. Vet Microbiol 2012, 158:123-128.

33. Ahrens $P$, Andresen LO: Cloning and sequence analysis of genes encoding Staphylococcus hyicus exfoliative toxin types A, B, C, and D. J Bacteriol 2004, 186:1833-1837.

34. Cunha MLRS, Calsolari RAO: Toxigenicity in Staphylococcus aureus and coagulase-negative staphylococci: epidemiological and molecular aspects. Microbiology Insights 2008, 1:13-24.

35. Okee MS, Joloba ML, Okello M, Najjuka FC, Katabazi FA, Bwanga F, Nanteza A, Kateete DP: Prevalence of virulence determinants in Staphylococcus epidermidis from ICU patients in Kampala, Uganda. J Infect Dev Ctries 2012, 6:242-250.

36. Devriese LA, Schleifer $\mathrm{KH}$, Adegoke GO: Identification of coagulasenegative staphylococci from farm animals. J App/ Bacteriol 1985, 58:45-55.

37. Holtfreter S, Bauer K, Thomas D, Feig C, Lorenz V, Roschack K, Friebe E, Selleng K, Lövenich S, Greve T, Greinacher A, Panzig B, Engelmann S, Lina G, 
Bröker BM: egc-Encoded superantigens from Staphylococcus aureus are neutralized by human sera much less efficiently than are classical staphylococcal enterotoxins or toxic shock syndrome toxin. Infect Immun 2004, 72:4061-4071.

38. Lowe BA, Marsh TL, Isaacs-Cosgrove N, Kirkwood RN, Kiupel M, Mulks MH: Microbial communities in the tonsils of healthy pigs. Vet Microbiol 2011, 147:346-357.

39. Butler JE, Lager KM, Splichal I, Francis D, Kacskovics I, Sinkora M, Wertz N, Sun J, Zhao Y, Brown WR, DeWald R, Dierks S, Muyldermans S, Lunney JK, McCray PB, Rogers CS, Welsh MJ, Navarro P, Klobasa F, Habe F, Ramsoondar J: The piglet as a model for $B$ cell and immune system development. Vet Immunol Immunopathol 2009, 128:147-170.

40. Arriola CS, Guere ME, Larsen J, Skov RL, Gilman RH, Gonzalez AE, Silbergeld EK: Presence of methicillin-resistant Staphylococcus aureus in pigs in Peru. PLOS One 2011, 6:e28529.

41. Lin Y, Barker E, Kislow J, Kaldhone P, Stemper ME, Pantrangi M, Moore FM, Hall M, Fritsche TR, Novicki T, Foley SL, Shukla SK: Evidence of multiple virulence subtypes in nosocomial and community-associated MRSA genotypes in companion animals from the upper midwestern and northeastern United States. Clin Med Res 2011, 9:7-16.

42. Bradley PA, Bourne FJ, Brown PJ: The respiratory tract immune system in the pig. I. Distribution of immunoglobulin-containing cells in the respiratory tract mucosa. Vet Pathol 1976, 13:81-89.

43. Bailey M, Haverson K, Inman C, Harris C, Jones P, Corfield G, Miller B, Stokes $C$ : The influence of environment on development of the mucosal immune system. Vet Immunol Immunopathol 2005, 108:189-198.

44. Macpherson AJ, Slack E: The functional interactions of commensal bacteria with intestinal secretory IgA. Curr Opin Gastroenterol 2007, 23:673-678

doi:10.1186/1297-9716-44-4

Cite this article as: Crombé et al:: Serological profiles in nursery piglets colonized with Staphylococcus aureus. Veterinary Research 2013 44:4.

\section{Submit your next manuscript to BioMed Central and take full advantage of:}

- Convenient online submission

- Thorough peer review

- No space constraints or color figure charges

- Immediate publication on acceptance

- Inclusion in PubMed, CAS, Scopus and Google Scholar

- Research which is freely available for redistribution 